\title{
A GLP-1 receptor agonist attenuates human islet amyloid polypeptide-induced autophagy and apoptosis in MIN6 cells
}

\author{
XIONG CHEN $^{1 *}$, TINGTING HUANG $^{1 *}$, YUJUAN SHI $^{1 *}$, LUYIN WANG $^{1}$, \\ WEI $\mathrm{LI}^{2}$, FEIXIA SHEN ${ }^{1}$ and XUEMEI GU ${ }^{1}$ \\ ${ }^{1}$ Department of Endocrinology, The First Affiliated Hospital of Wenzhou Medical University; \\ ${ }^{2}$ Department of Life Sciences, Wenzhou Medical University, Wenzhou, Zhejiang 325000, P.R. China
}

Received January 25, 2018; Accepted September 21, 2018

DOI: $10.3892 / \mathrm{mmr} .2018 .9741$

\begin{abstract}
Type 2 diabetes mellitus (T2DM) is characterized by the dysfunction and loss of pancreatic islet $\beta$-cells, in part due to islet amyloid deposits derived from islet amyloid polypeptide (IAPP). The glucagon-like peptide-1 (GLP-1) receptor agonist exendin-4 enhances the insulin secretory response by increasing $\beta$-cell mass in T2DM. However, it is unknown whether exendin- 4 protects $\beta$-cells from IAPP-mediated autophagy and apoptosis. In the present study, reverse transcription-quantitative polymerase chain reaction, ELISA and western blotting were used to detected the mRNA and protein expression of insulin/hIAPP and other signaling molecules, while the mechanisms underlying these effects were also determined. Exendin-4 increased the level of insulin secretion, which was greater than that of IAPP, leading to a beneficial IAPP/insulin secretion pattern. In MIN6 cells incubated with $25 \mathrm{mM}$ glucose, exendin-4 decreased the ratio of light chain 3 (LC3)-II/I, which was accompanied by an increase in $\mathrm{p} 62$ protein. In a hIAPP-overexpressing MIN6 cell model, exendin- 4 prevented the hIAPP-induced increase in the LC3II/I ratio and decrease in p62 expression. In addition, exendin-4 pretreatment reduced hIAPP-induced activation of cleaved caspase-3, suggesting that exendin-4 may protect MIN6 cells against apoptosis. Taken together, the results highlight hIAPP as a critical mediator of $\beta$-cell loss and suggest that the GLP-1 receptor agonist exendin-4 may be a potential therapeutic agent for hIAPP-induced $\beta$-cell damage.
\end{abstract}

Correspondence to: Dr Xuemei Gu, Department of Endocrinology, The First Affiliated Hospital of Wenzhou Medical University, 3 Nanbaixiang, Ouhai, Wenzhou, Zhejiang 325000, P.R. China

E-mail: snowgxm@126.com

*Contributed equally

Key words: glucagon-like peptide-1, exendin-4, islet amyloid polypeptide, autophagy, apoptosis

\section{Introduction}

Type 2 diabetes mellitus (T2DM) is characterized by loss of $\beta$-cell mass, dysfunction of $\beta$-cells and increased $\beta$-cell apoptosis (1). Islet pathology in T2DM is characterized by the accumulation of extracellular islet amyloid deposits derived from islet amyloid polypeptide (IAPP), which is also known as amylin (2). IAPP, a 4-kDa peptide hormone composed of 37 amino acids, is synthesized and co-secreted from pancreatic $\beta$-cells along with insulin. Although extracellular islet amyloid is relatively inert, the intracellular membrane-permeant toxic IAPP oligomers that form within $\beta$-cells in T2DM are thought to induce $\beta$-cell dysfunction and apoptosis $(3,4)$. A previous study investigating the mechanisms involved in the human IAPP (hIAPP)-induced onset of the multidimensional pathogenic response in $\beta$-cells suggested that impaired autophagy, endoplasmic reticulum (ER) stress, reactive oxygen species activation, membrane disruption and receptor-mediated signal transduction cascades may serve a role in this process (5).

Glucagon-like peptide-1 (GLP-1) is a gastrointestinal hormone primarily secreted by L cells in the intestine in response to food intake. GLP-1 has been shown to ameliorate hyperglycemia by augmenting $\beta$-cell insulin secretion and by imposing a low risk of induced hypoglycemia (6). An increasing number of studies have revealed that GLP-1 exhibits beneficial pleiotropic effects in $\beta$-cells, including attenuating oxidative stress (7), the inflammatory response (8) and unbalanced autophagy (9), and enhancing cellular proliferation and survival (10).

Amylin and structurally related calcitonin gene-related peptide (CGRP) restrain the stimulatory effect of GLP-1 (7-36) amide (11). GLP-1 protects the brain from $\beta$-amyloid peptide toxicity $(12,13)$. Furthermore, Park et al (14) revealed that a GLP-1 receptor agonist may preserve $\beta$-cells by restoring impaired pro-hIAPP processing and reducing hIAPP aggregation. However, further investigation into the exendin-4-mediated protective effects on hIAPP-induced damage in pancreatic $\beta$-cells is still required $(15,16)$. In addition, it is also thought that complex interactions may exist between GLP-1 and IAPP.

Autophagy is an intracellular process characterized by dynamic rearrangement of subcellular membranes that sequester cytoplasm, protein aggregates, pathogens and 
organelles for delivery to vacuoles and lysosomes, where the components are degraded and recycled (17). Autophagy is important for maintaining protein quality, which is crucial for diverse biological processes $(17,18)$. Several studies have revealed that human IAPP induces $\beta$-cell mass loss by targeting autophagy $(19,20)$; however, it is not known whether hIAPP-induced islet $\beta$-cell toxicity attenuation by GLP-1 is associated with alterations in autophagy.

The aim of the present study was to elucidate the hIAPP secretion patterns and insulin stimulatory effects of exendin-4 in MIN6 cells and to determine whether a GLP-1 receptor agonist has anti-autophagic and anti-apoptotic effects on hIAPP overexpression in MIN6 cells.

\section{Materials and methods}

Cell culture and transfection. MIN-6 cells, purchased from China Center for Type Culture Collection (Wuhan, China) were cultured in Dulbecco's modified Eagle's medium containing $25 \mathrm{mM}$ glucose (Thermo Fisher Scientific, Inc., Waltham, MA, USA) with $10 \%$ fetal bovine serum (Gibco; Thermo Fisher Scientific, Inc.), $100 \mathrm{U} / \mathrm{ml}$ penicillin (Beyotime Institute of Biotechnology, Shanghai, China) and $100 \mathrm{mg} / \mathrm{ml}$ streptomycin-sulfate (Beyotime Institute of Biotechnology, Jiangsu, China) at $37^{\circ} \mathrm{C}$ and $100 \%$ humidified air containing $5 \% \mathrm{CO}_{2}$ until $80-90 \%$ confluence was reached.

Cell transfection was performed using Lipofectamine $3000^{\mathrm{TM}}$ (Invitrogen; Thermo Fisher Scientific, Inc.) according to the manufacturer's instructions. Briefly, cells were seeded at $1 \times 10^{6}$ cells/well in a 6 -well plate with $2 \mathrm{ml}$ of growth medium without antibiotics at $37^{\circ} \mathrm{C}$. Once $70 \%$ confluence was reached, MIN-6 cells were divided into three groups according to transfection: hIAPP, blank plasmid and control group without plasmid. In hIAPP or blank plasmid group, cells were transfected with $2.5 \mu \mathrm{g}$ of hIAPP plasmid or empty plasmid DNA (Beyotime Institute of Biotechnology, Jiangsu, China) and $7.5 \mu$ l of Lipofectamine ${ }^{\circledR} 3000$ (Beyotime Institute of Biotechnology, Jiangsu, China), respectively. In the control group, cells were culture in growth medium without antibiotics. After $8 \mathrm{~h}$ at $37^{\circ} \mathrm{C}$, the medium was changed to growth medium containing antibiotics. At $24 \mathrm{~h}$ post-transfection, MIN-6 cells were further cultured at $37^{\circ} \mathrm{C}$ in 6 -well plates until $70 \%$ confluence was reached. Then, $100 \mathrm{nM}$ Exendin 4 was added to the culture medium for $24 \mathrm{~h}$. Untransfected MIN-6 cells treated with rapamycin only were used as positive controls.

Determination of insulin and IAPP levels by enzyme-linked immunosorbent assay (ELISA). Insulin and amylin levels in MIN-6 cells supernatants were determined using a mouse ELISA kit (cat. nos. BPE20353 and BPE20356) purchased from Shanghai Langton Biotechnology Co. Ltd. (Shanghai, China) according to the manufacturer's instructions. Absorbance at $450 \mathrm{~nm}$ was measured using an ELX800 Universal Microplate Reader (BioTek Instruments, Inc., Winooski, VT, USA). A standard curve was obtained using purified proteins supplied with the ELISA kit.

Reverse transcription-quantitative polymerase chain reaction (RT-qPCR). Total RNA was extracted from cells using TRIzol (Invitrogen; Thermo Fisher Scientific, Inc.). cDNA was reverse transcribed with a SYBR Premix Ex Taq II RT kit from Takara Bio, Inc. (Otsu, Japan). The RT reaction was conducted under the following conditions: $37^{\circ} \mathrm{C}$ for $15 \mathrm{~min}$ and $85^{\circ} \mathrm{C}$ for $5 \mathrm{sec}$; then held at $4^{\circ} \mathrm{C}$. The qPCR was performed on a CFX96 instrument (Bio-Rad Laboratories, Inc.) with SYBR Premix Ex Taq (Takara Bio, Inc., Otsu, Japan). The primers used to amplify insulin, IAPP and $\beta$-actin genes, were synthesized by Invitrogen (Thermo Fisher Scientific, Inc.): Mouse insulin sense, 5'-TGTTGGTGCACTTCCTACCC-3' and antisense, 5'-ACACACCAGGTAGAGAGCCT-3'; mouse IAPP sense, 5'-AGATGGACAAACGGAAGTGC-3' and antisense 5'-TTG GTTGGTGGGAGGACTG-3'; and mouse $\beta$-actin sense 5'-GGGAAATCGTGCGTGAC-3' and antisense 5'-AGG CTGGAAAAGAGCCT-3'. qPCR was conducted under the following conditions: $95^{\circ} \mathrm{C}$ for $5 \mathrm{~min}$, followed by 40 cycles of $95^{\circ} \mathrm{C}$ for $5 \mathrm{sec}, 60^{\circ} \mathrm{C}$ for $30 \mathrm{sec}$ and $72^{\circ} \mathrm{C}$ for $10 \mathrm{sec}$. The melting procedure was as follows: $30 \mathrm{sec}$ at $95^{\circ} \mathrm{C}$, followed by 40 cycles of $15 \mathrm{sec}$ at $95^{\circ} \mathrm{C}$ and $60 \mathrm{sec}$ at $60^{\circ} \mathrm{C}$. Gene expression was quantified using the $2^{-\Delta \Delta \mathrm{Cq}}$ method (21); the relative amount of each gene was normalized to that of $\beta$-actin, and the result is expressed as a ratio of the relative amount.

Methyl thiazolyl tetrazolium (MTT) assay. MIN6 cells were seeded $\left(4 \times 10^{3} /\right.$ well) in 96 -well plates and incubated at $37^{\circ} \mathrm{C}$ for $24 \mathrm{~h}$. The cells were then cultured with 25,50 or $100 \mathrm{nM}$ exendin- 4 or an equal volume of DMSO for $24 \mathrm{~h}$ and subjected to an MTT assay. An MTT $(0.5 \mathrm{mg} / \mathrm{ml})$ solution prepared in phosphate-buffered saline was added to each well, and the plates were then incubated at $37^{\circ} \mathrm{C}$ in a $5 \% \mathrm{CO}_{2}$-humidified atmosphere for $4 \mathrm{~h}$. Subsequently, the cells were treated with $150 \mu \mathrm{l}$ DMSO, and the optical density was detected with an ELX800 Universal Microplate Reader (BioTek Instruments, Inc.) at a wavelength of $630 \mathrm{~nm}$. Viability was defined as the ratio (expressed as a percentage) of the absorbance of exendin-4-treated cells to that of DMSO-treated cells.

Western blot analysis. Cells were harvested and lysed for protein isolation with total protein extraction reagent (cat. no. AR0103; Boster Biological Technology, Pleasanton, CA, USA). Protein concentration was determined with the bicinchoninic acid protein assay. Protein samples (50 $\mu \mathrm{g} /$ lane) were separated by $12 \%$ SDS-PAGE, then electrotransferred onto polyvinylidene fluoride membranes (Bio-Rad Laboratories, Inc.). Following preincubation in blocking buffer [5\% non-fat milk in Tris-buffered saline containing $0.05 \%$ Tween-20 (TBS-T)] for $1.5 \mathrm{~h}$ at room temperature, the membranes were incubated with primary antibodies against sequestosome 1/p62 (1:1,000; cat. no. 8025, Cell Signaling Technology, Inc., Danvers, MA, USA), light chain 3 (LC3, 1:1,000; cat. no. 3868; Cell Signaling Technology, Inc.), IAPP (1:1,000; cat. no. PA5-29713; Thermo Fisher Scientific, Inc.), cleaved caspase-3 (1:1,000; cat. no. 9664; Cell Signaling Technology, Inc.) or $\beta$-actin $(1: 5,000$; cat. no. BS6007M; Bioworld Technology, Inc., St. Louis Park, MN, USA) for $12 \mathrm{~h}$ at $4^{\circ} \mathrm{C}$. The membranes were then washed in TBS-T and incubated with horseradish peroxidase-conjugated secondary antibodies (1:5,000; cat. nos. IgGA0208 and IgGA0216; Beyotime Institute of Biotechnology) for 1-2 $\mathrm{h}$ at room temperature. Reactions were visualized with enhanced chemiluminescence reagents (Bio-Rad Laboratories, Inc., Hercules, CA, USA). 

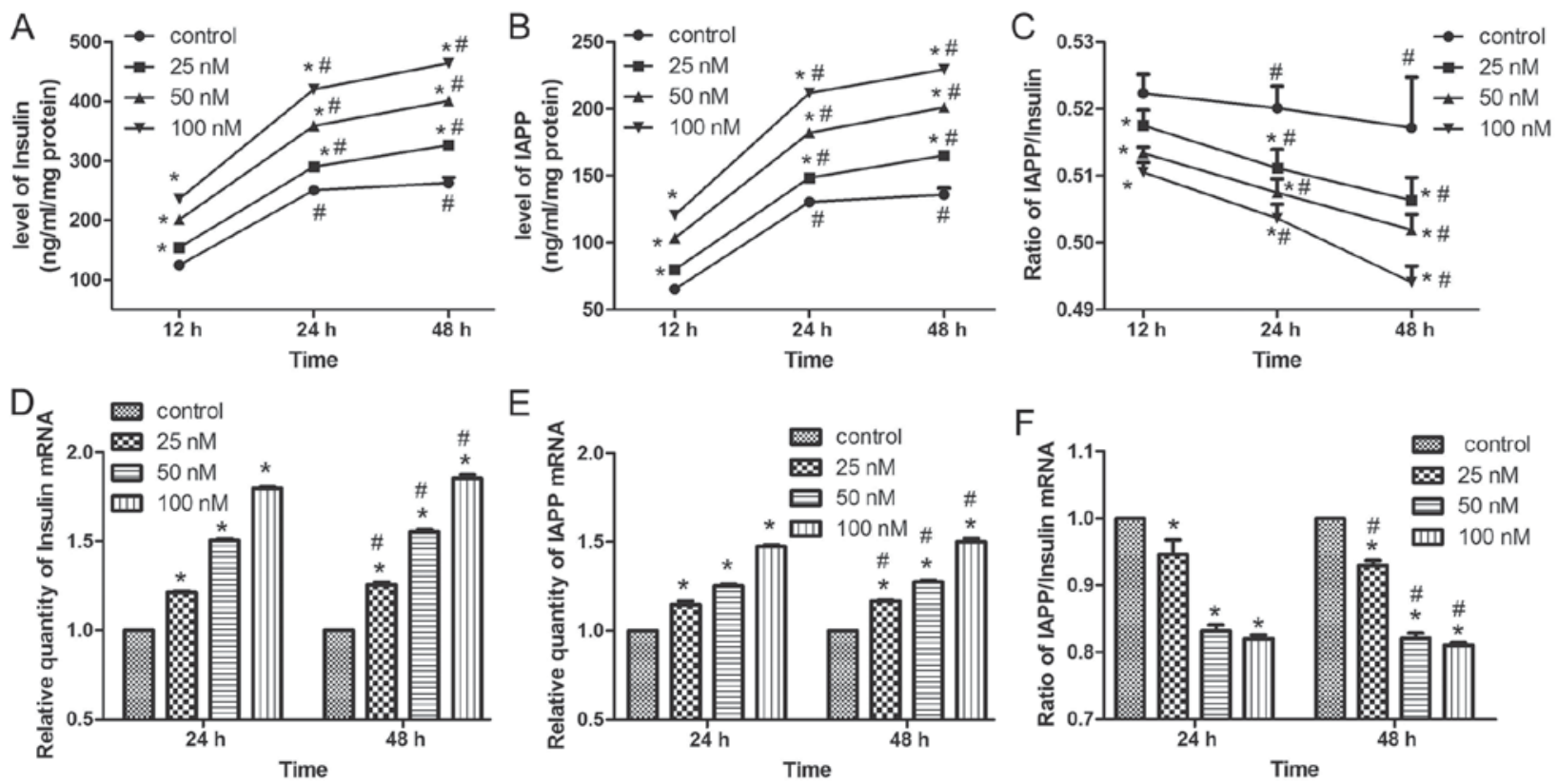

Figure 1. IAPP/insulin levels in exendin-4-treated MIN6 cells. MIN6 cells were subjected to various concentrations (25, 50 or $100 \mathrm{nM})$ of exendin-4 for the indicated times $(12,24$, or $48 \mathrm{~h})$. Cell supernatants were collected and analyzed by ELISA. Total RNA was extracted and analyzed by reverse transcription-quantitative polymerase chain reaction. Detection of (A) insulin and (B) IAPP protein levels in the conditioned medium from MIN6 cells incubated with exendin-4. (C) Ratio of the IAPP/insulin protein level. mRNA levels of (D) insulin and (E) IAPP in MIN6 cells incubated with exendin-4. (F) Ratio of the IAPP/insulin mRNA level. Data are presented as the mean \pm standard error of the mean $\left(\mathrm{n}=3 /\right.$ group). ${ }^{*} \mathrm{P}<0.05$ vs. control at the corresponding time point; ${ }^{\#} \mathrm{P}<0.05 \mathrm{vs} .12 \mathrm{~h}$ at the corresponding concentration treatment. IAPP, islet amyloid polypeptide.

Densitometric analysis was performed with by ImageJ version 1.46r (National Institutes of Health, Bethesda, MD, USA).

Statistical analyses. Data are presented as the mean \pm standard error of the mean. Statistical significance was assessed by one-way analysis of variance with a post-hoc Student-Newman-Keuls test for multiple comparisons using GraphPad Pro software (GraphPad Software, Inc., La Jolla, CA, USA). $\mathrm{P}<0.05$ was considered to indicate a statistically significant difference.

\section{Results}

Insulin/IAPP secretion patterns of MIN6 cells following exendin-4 pretreatment. As exendin-4 stimulates insulin secretion (22), alterations in the levels and secretion patterns of insulin and IAPP in MIN6 cells were investigated following treatment with the GLP-1 receptor agonist, exendin-4. Insulin and IAPP secretion increased significantly in time- and dose-dependent manners (Fig. 1A and B). As the increase in the level of insulin secretion was greater than that of IAPP, the IAPP/insulin ratio decreased with longer treatment times and higher concentrations of exendin-4 (Fig. 1C). In addition, the levels of IAPP mRNA expression were significantly increased in a concentration- and time-dependent manner; however, the IAPP/insulin mRNA ratio decreased (Fig. 1D-F).

Cell viability. MTT assays were performed to examine the activities of different exendin-4 concentrations $(25,50$ or $100 \mathrm{nM}$ ) in MIN6 cells. As shown in Fig. 2A, cell viability increased significantly in a time- and dose-dependent manner (Fig. 2A).
Exendin-4 reduces autophagy in MIN6 cells. The impact of $\beta$-cell autophagy has been proposed to be beneficial (23) and detrimental (24) to cell survival. To further characterize the positive effects of exendin-4 pretreatment on MIN6 cells, the present study assessed changes in the protein levels the autophagy markers, LC3II/I and p62 (Fig. 2B). Exendin-4 pretreatment reduced the LC3II/I ratio, which was accompanied by an increase in the level of p62 (Fig. 2B-D).

hIAPP-overexpression MIN6 cell model. Exendin-4 has been reported to inhibit hIAPP-induced insulinoma (INS-1E) cell death (15). To investigate the interactions between GLP-1 and IAPP, a hIAPP-overexpression MIN6 cell model was established (Fig. 3). The protein and mRNA expression levels of hIAPP were significantly upregulated following transfection with the hIAPP-overexpression plasmid into MIN6 cells (Fig. 3).

Exendin-4 protects MIN6 cells against hIAPP-induced autophagy and apoptosis. As shown in Fig. 4A, C and D, there was a significant increase in the LC3II/I ratio and decrease in p62 expression in MIN6 cells overexpressing hIAPP; these results were comparable to those achieved with treatment with rapamycin, an autophagy inducer. However, autophagy activation was significantly attenuated by exendin- 4 pretreatment. Cleaved caspase-3, the active form of caspase-3, was assessed to confirm apoptosis. Cleaved caspase-3 levels were significantly increased in hIAPP-overexpressing MIN6 cells when compared with control cells. However, the increased level of cleaved caspase-3 was reversed by exendin-4 pretreatment. These results indicated that hIAPP induced autophagy and apoptosis, whereas exendin-4 attenuated these effects (Fig. 4B and E). 


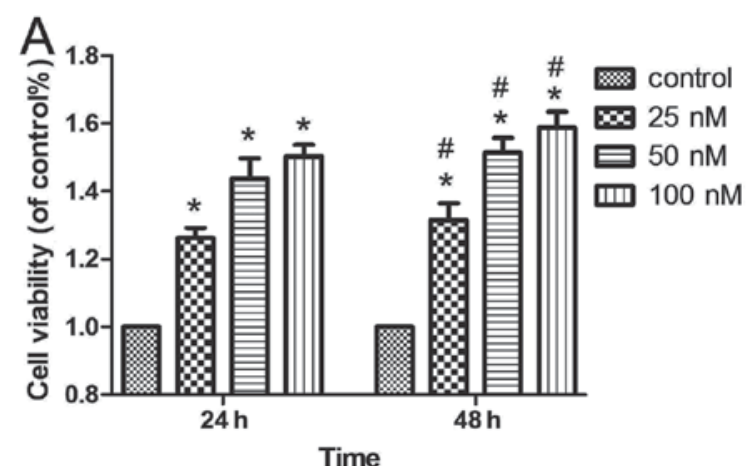

B
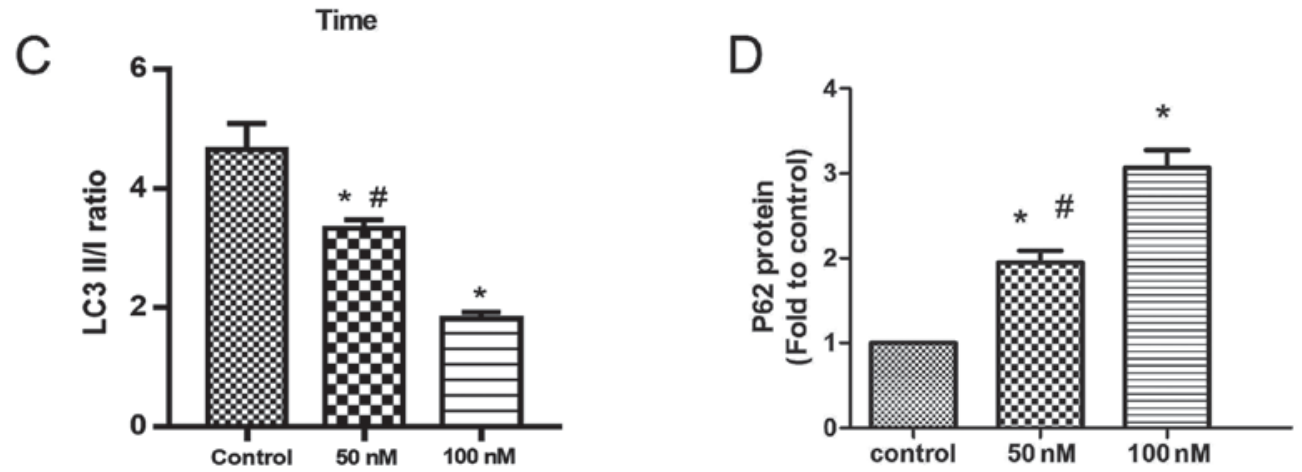

Figure 2. Exendin-4 reduces autophagy in MIN6 cells. (A) Viability of MIN6 cells exposed to exendin-4. MIN6 cells were treated with or without exendin-4 $(25,50$ or $100 \mathrm{nM})$ for 24 or $48 \mathrm{~h}$. Cell viability was measured using the MTT assay and was calculated as a percentage of the controls. "P<0.05 vs. control at the corresponding time point; ${ }^{\#} \mathrm{P}<0.05 \mathrm{vs} .12 \mathrm{~h}$ at the corresponding concentration treatment. (B) Autophagy in MIN6 cells treated with exendin-4. MIN6 cells were treated with or without exendin-4 (50 or $100 \mathrm{nM})$ for $24 \mathrm{~h}$. Representative western blot analysis of LC3 and p62 expression in MIN6 cells treated with exendin-4. (C and D) The densitometric quantification of the western blot for (C) LC3I/II and (D) p62 was performed via normalization of the band density of the indicated protein to that of the loading control protein. Data are presented as the mean \pm standard error of the mean ( $\mathrm{n}=3 / \mathrm{group})$. "P<0.05 vs. the control group; ${ }^{*} \mathrm{P}<0.05$ vs. $100 \mathrm{nM}$ exendin-4. LC3, light chain 3.

\section{Discussion}

It is now widely accepted that $\beta$-cell failure, including decreased $\beta$-cell mass and insulin secretion, leads to T2DM. GLP-1 receptor agonist therapies have shown promising effects in terms of positively affecting $\beta$-cell function and increasing $\beta$-cell mass $(20,22)$ however, the underlying mechanisms remain unclear. In the present study, exendin- 4 pretreatment improved the insulin and IAPP secretion pattern and cell viability in a time- and dose-dependent manner. The results support a novel model in which hIAPP induces autophagy activation, leading to MIN6 cell apoptosis. Pretreatment with exendin- 4 reversed hIAPP-induced apoptosis and inhibited autophagy.

As IAPP is co-secreted with insulin, insulin resistance causes IAPP overexpression, which may contribute to amyloidogenesis. Xiao et al (25), demonstrated that short-term exposure to high IAPP concentrations inhibited glibenclamide-induced K (adenosine triphosphate) channel closure and decreased calcium influx, which may ultimately lead to reduced insulin secretion in INS-1 cells. Insulin has been shown to prevent IAPP aggregation (26). In addition, a change in the IAPP/insulin ratio, rather than an increase in IAPP levels, is vital for amyloid formation (27). Circulating levels of GLP-1 directly stimulate $\beta$-cell insulin secretion through protein kinase $\mathrm{C}$-dependent transient receptor potential cation channel subfamily M member 4 (TRPM4) and TRPM5 activation (28). However, little is known about the effects of GLP-1 receptor agonists on stimulating endogenously released IAPP instead of insulin. By examining the exendin-4-induced secretion pattern of IAPP and insulin in MIN6 cells incubated with $25 \mathrm{mM}$ glucose, the present study revealed that exendin-4 increased the protein and mRNA levels of insulin, as well as those of IAPP, in a dose- and time-dependent manner. In addition, the IAPP/insulin ratio decreased significantly with increasing concentrations and time. These results indicated that islet insulin release may be more sensitive than IAPP release is to exendin- 4 stimulation. According to the present results, beneficial IAPP/insulin secretion patterns in MIN6 cells can be enhanced by high exendin- 4 concentrations and long incubation times.

Autophagy is a crucial regulator of pancreatic $\beta$-cell homeostasis (29), and impaired autophagic machinery may lead to $\beta$-cell dysfunction and ultimately T2DM (30). The present study revealed that there was inhibition of autophagy activation with increasing concentrations of exendin-4 (50 and $100 \mathrm{nM}$ ) in MIN6 cells, and this inhibitory effect was also observed in $\beta$-cell viability in a dose-dependent manner. Consistent with the present results, a previous study reported that exendin- 4 protects against tacrolimus-induced pancreatic islet injury by regulating autophagy clearance (10). Zhao et al (31) also revealed that liraglutide exerts a protective effect in the presence of high glucose by inhibiting autophagy in HK-2 cells and in the kidneys of diabetic rats. Nonetheless, another previous study proposed that by activating autophagy, liraglutide exerts a protective effect on glucolipotoxicity and lipotoxicity in INS-1E $\beta$-cells (32). These findings suggest that the underlying mechanism of autophagic dysfunction under different conditions may determine the impact of GLP-1 receptor agonists. 


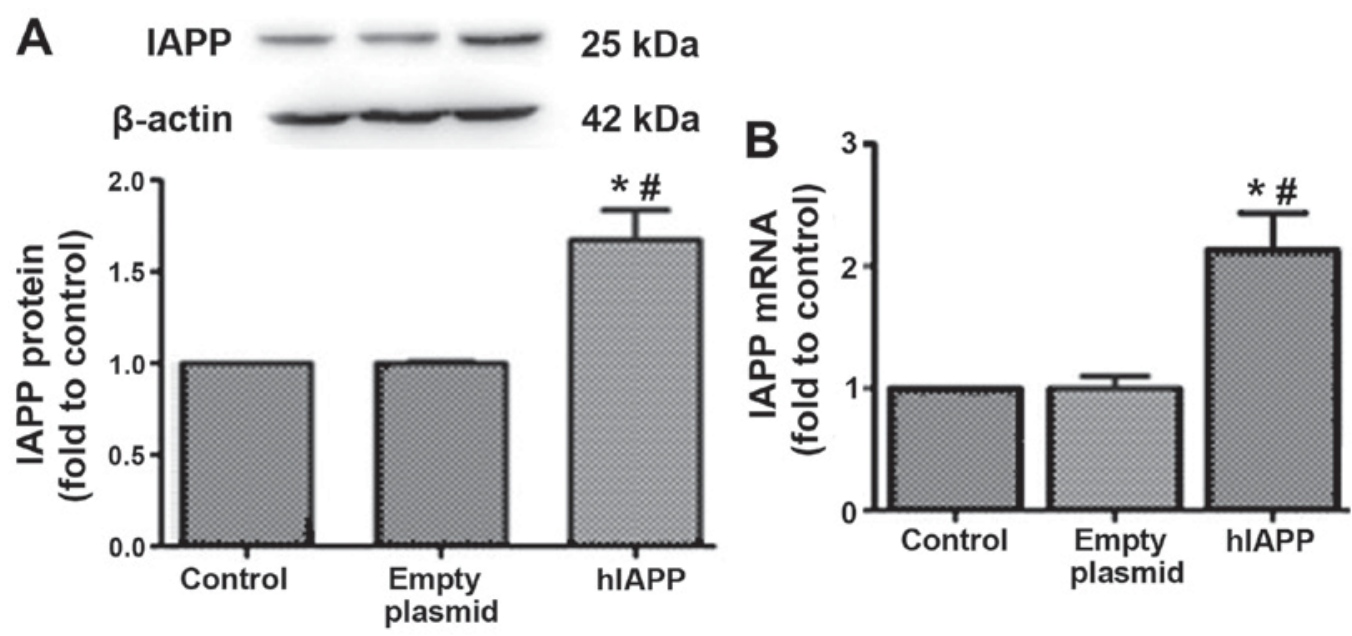

Figure 3. Change in IAPP level following transfection. (A) Western blot analysis of hIAPP expression in hIAPP-overexpressing MIN6 cells at the end of a $24 \mathrm{~h}$ treatment period (48 h post-transfection); $\beta$-Actin served as the loading control. The densitometric quantification of the western blot results was performed via normalization of the band density of the indicated protein to that of the loading control protein ( $\mathrm{n}=3$ per group). (B) The mRNA level of IAPP in IAPP-overexpressing MIN6 cells at the end of a $24 \mathrm{~h}$ treatment period ( $48 \mathrm{~h}$ post-transfection). Data are presented as mean \pm standard error of the mean ( $\mathrm{n}=3$ /group). ${ }^{\mathrm{P}}<0.05$ vs. the control; ${ }^{\mathrm{P}} \mathrm{P}<0.05$ vs. the empty plasmid. hIAPP, human islet amyloid polypeptide.
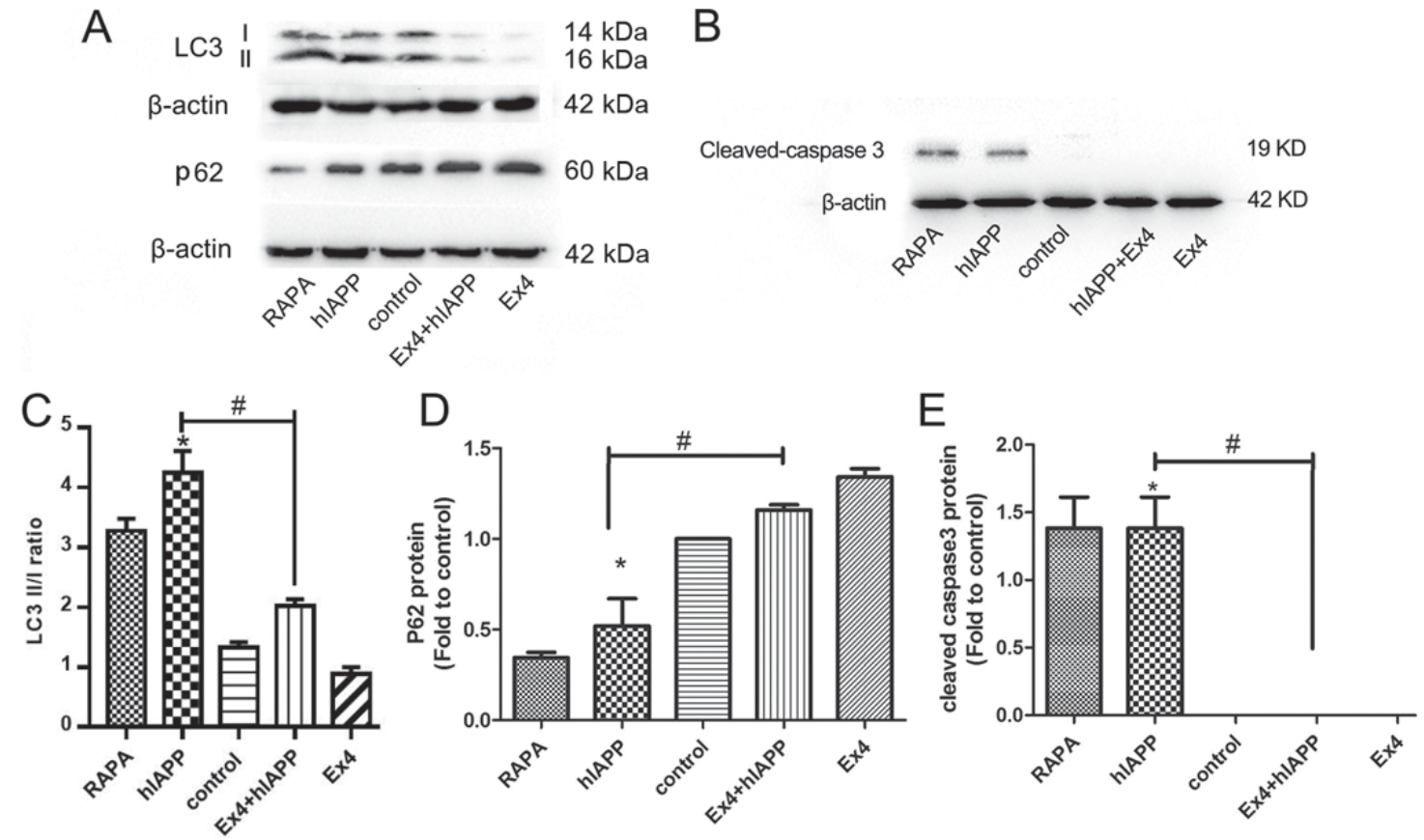

Figure 4. Exendin-4 protects MIN6 cells from hIAPP-induced autophagy and apoptosis. At 24 h post-transfection, cells were treated with or without exendin-4 for $24 \mathrm{~h}$. Rapamycin was used as a positive control for autophagy. Representative western blot analysis of (A) LC3 and p62 expression, and (B) cleaved caspase-3 expression in MIN6 cells treated with exendin-4. The densitometric quantification of the western blot results for (C) LC3I/II, (D) p62 and (E) cleaved caspase-3 was performed via normalization of the band density of the indicated protein to that of the loading control protein. Data are presented as mean \pm standard error of the mean ( $\mathrm{n}=3$ /group). ${ }^{*} \mathrm{P}<0.05$ vs. the control; ${ }^{\text {}} \mathrm{P}<0.05$, as indicated. hIAPP, human islet amyloid polypeptide; LC3, light chain 3 ; RAPA, Rapamycin; Ex4, exendin-4.

Shigihara et al (33), reported that increased insulin resistance may enhance the toxic potential of hIAPP and ultimately $\beta$-cell failure. Therefore, the present study evaluated the pathogenic role of hIAPP on autophagy in an hIAPP-overexpression MIN6 cell model as well as the possible reversion capacity of exendin- 4 pretreatment. The results indicated that exendin- 4 pretreatment attenuated the hIAPP-induced increase in the LC3II/I ratio and decrease in $\mathrm{p} 62$ expression, both of which are indicators of autophagy. Previous studies have demonstrated that GLP-1 exerts protective effects by inhibiting excessive autophagy $(10,34,35)$. All of these studies, taken together with the present results, suggest that exendin-4 may exhibit protective effects by attenuating hIAPP-induced autophagy in MIN6 cells.

GLP-1 receptor agonists have been shown in many paradigms to enhance $\beta$-cell survival by decreasing apoptosis (36-38). For example, an in vitro study reported that GLP-1 receptor agonists protect $\beta$-cells from injury-induced apoptosis, 
including cytokine-, ER stress- and glucolipotoxicity-induced apoptosis (6). The present results indicated that exendin-4 alleviated hIAPP-induced apoptosis to levels comparable with those of the control group. These results are consistent with our previous findings in clonal insulinoma cells (INS-1E cell line) (15). Whether autophagy is the driver of cell death or a pro-survival process in response to certain stress conditions remains controversial. Although autophagy was initially described as a cytoprotective response under nutrient deprivation, a series of studies have suggested that autophagy serves a vital role in promoting cell death, including apoptosis (39-41). Future studies are required to define the precise mechanisms underlying the effects of exendin- 4 on autophagy and apoptosis.

Targeting autophagy and apoptosis inhibition represents a novel therapeutic strategy against $\beta$-cell failure in diabetic patients. However, the majority of traditional anti-diabetic agents are unable to induce any direct anti-autophagic or anti-apoptotic benefits in dysfunctional $\beta$-cells during diabetes progression. Multiple mechanisms are involved in the pathogenesis of hIAPP-induced $\beta$-cell failure, such as autophagy and apoptosis $(42,43)$. The results of the present study further support the therapeutic potential of exendin-4 in treating diabetic $\beta$-cell failure by attenuating hIAPP-induced autophagy and apoptosis. With anti-autophagic and anti-apoptotic properties, exendin-4 may gain more attention for $\beta$-cell failure treatment.

In conclusion, the present study revealed that a beneficial IAPP/insulin secretion pattern was achieved in response to exendin-4 pretreatment in MIN6 cells, and this was accompanied by autophagy inhibition. hIAPP overexpression enhanced autophagy and apoptosis in MIN6 cells, and these processes were attenuated by exendin- 4 pretreatment. Although more research is required to examine the underlying protective mechanism of GLP-1 receptor agonists on $\beta$-cells, the results highlight the potential therapeutic application of GLP-1 receptor agonists in the treatment of T2DM.

\section{Acknowledgements}

Not applicable.

\section{Funding}

This study was supported by the Clinical Medicine Research Fund of the Chinese Medical Association (grant no. 13020110396) and Zhejiang Provincial Natural Science Foundation of China (grant no. LY16H070006).

\section{Availability of data and materials}

The datasets used and/or analyzed during the present study are available from the corresponding author on reasonable request.

\section{Authors' contributions}

$\mathrm{XC}, \mathrm{TH}$ and YS performed the experiments. XG and FS designed the study. WL and FS contributed essential reagents and/or tools. TH, YS, LW and WL analyzed and interpreted the data. $\mathrm{XG}$ and $\mathrm{XC}$ wrote the paper.

\section{Ethics approval and consent to participate}

Not applicable.

\section{Patient consent for publication}

Not applicable.

\section{Competing interests}

The authors declare that they have no competing interests.

\section{References}

1. Butler AE, Janson J, Bonner-Weir S, Ritzel R, Rizza RA and Butler PC: Beta-cell deficit and increased beta-cell apoptosis in humans with type 2 diabetes. Diabetes 52: 102-110, 2003.

2. Haataja L, Gurlo T, Huang CJ and Butler PC: Islet amyloid in type 2 diabetes and the toxic oligomer hypothesis. Endocr Rev 29: 303-316, 2008.

3. Gurlo T, Ryazantsev S, Huang CJ, Yeh MW, Reber HA, Hines OJ, O'Brien TD, Glabe CG and Butler PC: Evidence for proteotoxicity in beta cells in type 2 diabetes: Toxic islet amyloid polypeptide oligomers form intracellularly in the secretory pathway. Am J Pathol 176: 861-869, 2010.

4. Fernández MS: Human IAPP amyloidogenic properties and pancreatic $\beta$-cell death. Cell Calcium 56: 416-427, 2014.

5. Akter R, Cao P, Noor H, Ridgway Z, Tu LH, Wang H, Wong AG, Zhang X, Abedini A, Schmidt AM and Raleigh DP: Islet amyloid polypeptide: Structure, function, and pathophysiology. J Diabetes Res 2016: 2798269, 2016.

6. Lavine JA and Attie AD: Gastrointestinal hormones and the regulation of $\beta$-cell mass. Ann N Y Acad Sci 1212: 41-58, 2010.

7. Lotfy M, Singh J, Rashed H, Tariq S, Zilahi E and Adeghate E: Mechanism of the beneficial and protective effects of exenatide in diabetic rats. J Endocrinol 220: 291-304, 2014.

8. Huang C, Yuan L and Cao S: Endogenous GLP-1 as a key self-defense molecule against lipotoxicity in pancreatic islets. Int J Mol Med 36: 173-185, 2015

9. Lim SW, Jin L, Jin J and Yang CW: Effect of exendin-4 on autophagy clearance in beta cell of rats with tacrolimus-induced diabetes mellitus. Sci Rep 6: 29921, 2016.

10. Lamont BJ and Andrikopoulos S: Hope and fear for new classes of type 2 diabetes drugs: Is there preclinical evidence that incretin-based therapies alter pancreatic morphology? J Endocrinol 221: T43-T61, 2014.

11. Göke R, McGregor GP and Göke B: Amylin alters the biological action of the incretin hormone GLP-1(7-36)amide. Life Sci 53: 1367-1372, 1993.

12. Bak AM, Egefjord L, Gejl M, Steffensen C, Stecher CW, Smidt K, Brock B and Rungby J: Targeting amyloid-beta by glucagon-like peptide-1 (GLP-1) in Alzheimer's disease and diabetes. Expert Opin Ther Targets 15: 1153-1162, 2011.

13. Qin Z, Sun Z, Huang J, Hu Y, Wu Z and Mei B: Mutated recombinant human glucagon-like peptide-1 protects SH-SY5Y cells from apoptosis induced by amyloid-beta peptide (1-42). Neurosci Lett 444: 217-221, 2008

14. Park YJ, Ao Z, Kieffer TJ, Chen H, Safikhan N, Thompson DM, Meloche M, Warnock GL and Marzban L: The glucagon-like peptide-1 receptor agonist exenatide restores impaired pro-islet amyloid polypeptide processing in cultured human islets: Implications in type 2 diabetes and islet transplantation. Diabetologia 56: 508-519, 2013.

15. Fan R, Li X, Gu X, Chan JC and Xu G: Exendin-4 protects pancreatic beta cells from human islet amyloid polypeptide-induced cell damage: Potential involvement of AKT and mitochondria biogenesis. Diabetes Obes Metab 12: 815-824, 2010.

16. Aston-Mourney K, Hull RL, Zraika S, Udayasankar J, Subramanian SL and Kahn SE: Exendin-4 increases islet amyloid deposition but offsets the resultant beta cell toxicity in human islet amyloid polypeptide transgenic mouse islets. Diabetologia 54: 1756-1765, 2011.

17. Levine B and Klionsky DJ: Development by self-digestion: Molecular mechanisms and biological functions of autophagy. Dev Cell 6: 463-477, 2004. 
18. Nakai A, Yamaguchi O, Takeda T, Higuchi Y, Hikoso S, Taniike M, Omiya S, Mizote I, Matsumura Y, Asahi M, et al: The role of autophagy in cardiomyocytes in the basal state and in response to hemodynamic stress. Nat Med 13: 619-624, 2007.

19. Rivera JF, Costes S, Gurlo T, Glabe CG and Butler PC: Autophagy defends pancreatic $\beta$ cells from human islet amyloid polypeptide-induced toxicity. J Clin Invest 124: 3489-3500, 2014

20. Morita S, Sakagashira S, Shimajiri Y, Eberhardt NL, Kondo T, Kondo T and Sanke T: Autophagy protects against human islet amyloid polypeptide-associated apoptosis. J Diabetes Investig 2 48-55, 2011.

21. Livak KJ and Schmittgen TD: Analysis of relative gene expression data using real-time quantitative PCR and the 2(-Delta Delta C(T)) method. Methods 25: 402-408, 2001.

22. Asmar M and Holst JJ: Glucagon-like peptide 1 and glucose-dependent insulinotropic polypeptide: New advances. Curr Opin Endocrinol Diabetes Obes 17: 57-62, 2010.

23. Bachar-Wikstrom E, Wikstrom JD, Ariav Y, Tirosh B, Kaiser N, Cerasi E and Leibowitz G: Stimulation of autophagy improves endoplasmic reticulum stress-induced diabetes. Diabetes 62 : 1227-1237, 2013

24. Mir SU, George NM, Zahoor L, Harms R, Guinn Z and Sarvetnick NE: Inhibition of autophagic turnover in $\beta$-cells by fatty acids and glucose leads to apoptotic cell death. J Biol Chem 290: 6071-6085, 2015.

25. Xiao J, Li X, Zhao X, He B, Shang X, Han L, Wu G, Ding X and Zhu T: The effects and mechanism of islet amyloid polypeptide on insulin secretion in INS-1 cells stimulated by glibenclamide. Zhonghua Nei Ke Za Zhi 54: 214-218, 2015.

26. Westermark P, Andersson A and Westermark GT: Islet amyloid polypeptide, islet amyloid, and diabetes mellitus. Physiol Rev 91 : 795-826, 2011

27. Krizhanovskii C, Fred RG, Oskarsson ME, Westermark GT and Welsh N: Addition of exogenous sodium palmitate increases the IAPP/insulin mRNA ratio via GPR40 in human EndoC- $\beta \mathrm{H} 1$ cells. Ups J Med Sci 122: 149-159, 2017.

28. Shigeto M, Ramracheya R, Tarasov AI, Cha CY, Chibalina MV Hastoy B, Philippaert K, Reinbothe T, Rorsman N, Salehi A, et al: GLP-1 stimulates insulin secretion by PKC-dependent TRPM4 and TRPM5 activation. J Clin Invest 125: 4714-4728, 2015

29. Sheng Q, Xiao X, Prasadan K, Chen C, Ming Y, Fusco J, Gangopadhyay NN, Ricks D and Gittes GK: Autophagy protects pancreatic beta cell mass and function in the setting of a high-fat and high-glucose diet. Sci Rep 7: 16348, 2017.

30. Fujitani Y, Kawamori R and Watada H: The role of autophagy in pancreatic beta-cell and diabetes. Autophagy 5: 280-282, 2009.

31. Zhao X, Liu G, Shen H, Gao B, Li X, Fu J, Zhou J and Ji Q: Liraglutide inhibits autophagy and apoptosis induced by high glucose through GLP-1R in renal tubular epithelial cells. Int J Mol Med 35: 684-692, 2015.
32. Wang J, Wu J, Wu H, Liu X, Chen Y, Wu J, Hu C and Zou D: Liraglutide protects pancreatic $\beta$-cells against free fatty acids in vitro and affects glucolipid metabolism in apolipoprotein E-/- mice by activating autophagy. Mol Med Rep 12: 4210-4218, 2015.

33. Shigihara N, Fukunaka A, Hara A, Komiya K, Honda A, Uchida T, Abe H, Toyofuku Y, Tamaki M, Ogihara T, et al: Human IAPP-induced pancreatic $\beta$ cell toxicity and its regulation by autophagy. J Clin Invest 124: 3634-3644, 2014.

34. Guo H, Wang B, Li H, Ling L, Niu J and Gu Y: Glucagon-like peptide-1 analog prevents obesity-related glomerulopathy by inhibiting excessive autophagy in podocytes. Am J Physiol Renal Physiol 314: F181-F189, 2018.

35. Cai X, Li J, Wang M, She M, Tang Y, Li J, Li H and Hui H: GLP-1 treatment improves diabetic retinopathy by alleviating autophagy through GLP-1R-ERK1/2-HDAC6 signaling pathway. Int J Med Sci 14: 1203-1212, 2017.

36. Ferdaoussi M, Abdelli S, Yang JY, Cornu M, Niederhauser G, Favre D, Widmann C, Regazzi R, Thorens B, Waeber G and Abderrahmani A: Exendin-4 protects beta-cells from interleukin-1 beta-induced apoptosis by interfering with the c-Jun NH2-terminal kinase pathway. Diabetes 57: 1205-1215, 2008.

37. Kim MH, Kim EH, Jung HS, Yang D, Park EY and Jun HS: EX4 stabilizes and activates $\mathrm{Nrf} 2$ via $\mathrm{PKC} \delta$, contributing to the prevention of oxidative stress-induced pancreatic beta cell damage. Toxicol Appl Pharmacol 315: 60-69, 2017.

38. Zeng Z, Yu R, Zuo F, Zhang B, Ma H and Chen S: Recombinant Lactococcus lactis expressing bioactive exendin-4 to promote insulin secretion and beta-cell proliferation in vitro. Appl Microbiol Biotechnol 101: 7177-7186, 2017.

39. Petersen M, Hofius D and Andersen SU: Signaling unmasked: Autophagy and catalase promote programmed cell death. Autophagy 10: 520-521, 2014

40. Zhu J, Wang KZ and Chu CT: After the banquet: Mitochondrial biogenesis, mitophagy, and cell survival. Autophagy 9: 1663-1676, 2013

41. Law BY, Wang M, Ma DL, Al-Mousa F, Michelangeli F, Cheng SH, Ng MH, To KF, Mok AY, Ko RY, et al: Alisol B, a novel inhibitor of the sarcoplasmic/endoplasmic reticulum $\mathrm{Ca}(2+)$ ATPase pump, induces autophagy, endoplasmic reticulum stress, and apoptosis. Mol Cancer Ther 9: 718-730, 2010.

42. Abedini A and Schmidt AM: Mechanisms of islet amyloidosis toxicity in type 2 diabetes. FEBS Lett 587: 1119-1127, 2013.

43. Ahrén B, Winzell MS, Wierup N, Sundler F, Burkey B and Hughes TE: DPP-4 inhibition improves glucose tolerance and increases insulin and GLP-1 responses to gastric glucose in association with normalized islet topography in mice with beta-cell-specific overexpression of human islet amyloid polypeptide. Regul Pept 143: 97-103, 2007. 